\title{
A ANÁLISE DE DISCURSO CRÍTICA NO ESTUDO DE POLÍTICAS PÚBLICAS DE SAÚDE: EXEMPLO A PARTIR DE MUDANÇAS NA POLÍTICA SOBRE DROGAS NO BRASII
}

\author{
Yuri Fontenelle Lima Montenegro¹, Ana Karla Ramalho Paixão1, Natália Caldas Martins \\ Sales ${ }^{1}$, Aline Veras Morais Brilhante ${ }^{1} e$ Christina César Praça Brasil ${ }^{1}$ \\ 1Universidade de Fortaleza, Brasil. fontenellesh@gmail.com; karlaramalho284@gmail.com; natalia@unilab.edu.br; \\ alineveras@unifor.br; cpraca@unifor.br.
}

\begin{abstract}
Resumo. Introdução: No Brasil, as políticas sobre drogas passaram por modificações ao longo do tempo, carregando marcas a cada período histórico e interesse sanitário-político vivenciado. Com a ascensão do conservadorismo no país, percebeu-se um caráter antirreformista em mudanças concentradas na lei $n^{\circ} 13.840$, de 5 de junho de 2019. Assim, elencou-se a análise desta lei a fim de identificar a intencionalidade do discurso desta sobre os novos cuidados em saúde mental dispensados aos usuários e dependentes de drogas; Objetivos: Relatar a experiência do estudo de um documento normativo sobre drogas a partir da Análise de Discurso Crítica; Métodos: Pesquisa documental de abordagem qualitativa da lei $n^{\circ} 13.840$ e da Mensagem $n^{\circ} 239$ utilizando o método de Fairclough para análise tridimensional dos componentes: texto, prática discursiva e prática social do discurso; Resultados: Identificaram-se estratégias de controle da vida de pessoas que utilizam substância psicoativa no discurso da normativa. $O$ fomento da abstinência por meio da inserção de Comunidades Terapêuticas reflete a intencionalidade política atual. Identifica-se também o esvaziamento do controle social nas esferas decisórias em geral; Conclusões Identificam-se ameaças às conquistas do MRPB por meio das contradições do discurso na política, influenciando no desenvolvimento de práticas de cuidado opressoras.
\end{abstract}

Palavras-chave: Pesquisa Qualitativa; Saúde Mental; Política Pública; Abuso de Drogas

\section{CRITICAL DISCOURSE ANALYSIS IN THE STUDY OF PUBLIC HEALTH POLICIES: AN EXAMPLE FROM CHANGES IN DRUG POLICY IN BRAZIL.}

\begin{abstract}
Introduction: In Brazil, drug policies have undergone changes over time, bearing marks for each historical period and experienced sanitary-political interest. With the rise of conservatism in the country, an anti-reformist character was perceived in changes concentrated in Law $n^{\circ} 13,840$, of June 5,2019 . Thus, the analysis of this law was listed in order to identify the intentionality of its speech about the new mental health care provided to drug users and dependents; Goals: To report the experience of studying a normative document on drugs based on Critical Discourse Analysis; Methods: Documentary research with a qualitative approach to Law $n^{\circ} 13,840$ and Message $n^{\circ} 239$ using the Fairclough method for three-dimensional analysis of the components: text, discursive practice and social practice of discourse; Results: Biopower and life control strategies were identified for people who use psychoactive substances in the normative discourse. The promotion of abstinence through the insertion of Therapeutic Communities reflects the current political intent. The emptying of social control in decision-making spheres in general is also identified; Conclusions Threats to the MRPB's achievements are identified through the contradictions of the discourse in politics, influencing the development of oppressive care practices.
\end{abstract}

Keywords: Qualitative Research; Mental Health; Public Policy; Substance-Related Disorders

\section{INTRODUÇÃO}

O presente trabalho apresenta resultados parciais de uma dissertação de mestrado cujo objetivo é analisar as mudanças discursivas presentes nas políticas sobre drogas a partir de 
2017. Parte-se do pressuposto que o uso de álcool e de outras drogas, bem como os modelos de tratamento e as políticas públicas específicas são fenômenos histórico-sociais, cujas representações variam conforme elementos estruturais inseridos na historicidade. $O$ estudo dos documentos normativos das Políticas Públicas pode tornar manifesta as mudanças discursivas, evidenciando possíveis transições ideológicas na forma de compreender as questões associadas a esse fenômeno.

Até a contemporaneidade, as tensões ideologicas, contradições e disputas de poder que marcaram os documentos normativos regentes das políticas públicas sobre drogas as aproximou do paradigma do controle disciplinar (Delgado, 2019; Guimarães \& Rosa, 2019; Nunes, Lima Júnior, Portugal, \& Torrenté, 2019; M. A. B. Silva \& Abrahão, 2020; Teixeira, Ramôa, Engstrom, \& Ribeiro, 2017; Vargas \& Campos, 2019). Observa-se, por exemplo, a influência da adesão do Brasil à Conferência Internacional do Ópio, sediada em Haia no início do século XX, na elaboração de documentos marcados pela associação entre os saberes jurídico e psiquiátrico na construção de um tratamento compulsório e manicomial (Carvalho, 2014; Vargas \& Campos, 2019). São estes o Decreto $n^{\circ} 14.969$, de 3 de setembro de 1921, que aprovava a criação de um sanatório para "toxicômanos" e o Decreto $n^{\circ} 891$, de 25 de novembro de 1938, que caracterizava a "toxicomania" como doença de notificação compulsória cujo tratamento não poderia ocorrer em domicílio, apenas em regime de internação obrigatória ou facultativa (Vargas \& Campos, 2019).

A lentidão do Estado para prover a assistência proposta deixou lacunas que foram preenchidas por associações de médicos pautadas por um paradigma higienista, cuja perspectiva depreciativa a respeito do usuário de álcool e de outras drogas era dominante, compreendendo-o como degenerado ou desviante. (Santos \& Queiroz, 2016). As intervenções guiaram-se, portanto, por um tratamento de cunho moral, caracterizada pela internação, isolamento social e trabalho terapêutico (Bolonheis-Ramos \& Boarini, 2015). Destaca-se a influência da Liga Brasileira de Higiene Mental (LBHM) e a sua relação com o pensamento eugênico na concepção desse modelo de assistência. As ideias racistas, moralistas e xenofóbicas defendidas pela psiquiatria da LBHM, dentre outras coisas, difundiu o programa de "prevenção eugênica" que incluiu o combate ao alcoolismo de forma repressiva e autoritária, compreendendo-o também como causa de pobreza e degradação moral (Costa, 2006). 
O reordenamento ideológico proporcionado pela derrubada da ditadura, seguido do Movimento de Reforma Sanitária (MRS) e pela criação do Sistema Único de Saúde (SUS), corroboraram para o questionamento do paradigma higienista e o alavancar do Movimento de Reforma Psiquiátrica no Brasil (MRPB). Após a Lei no 10.216, de 6 de abril de 2001, marco importante para o MRPB, há a publicação de diversos documentos legislativos que passam a abordar a questão das drogas como problema de saúde ao invés de segurança pública, indicando a virada no eixo norteador das políticas sobre drogas.

O Decreto $n^{\circ}$ 4.345, de 26 agosto de 2002, prevê a distinção entre "usuário", "pessoa em uso indevido", "dependente" e "traficante", concebe a aplicação de penas alternativas e adota ações de redução de danos. A Portaria $n^{\circ} 2.197$, de 14 de outubro de 2004, dispõe sobre a atenção integral a usuários de álcool e outras drogas, concebendo a articulação entre equipamentos nos três níveis de atenção em vista da inserção comunitária e da redução de internações psiquiátricas. A Portaria $n^{\circ} 1.028$, de $1^{\circ}$ de julho de 2005 , define as ações de Redução de Danos em termos de público-alvo, tipos de ações e princípios norteadores, tais como os direitos humanos, liberdade e identidade dos usuários. A Lei $n^{\circ}$ 11.343, de 23 de agosto de 2006, endossa as mudanças anteriores, ao prever o investimento em alternativas esportivas, culturais, artísticas e profissionais como meios de inclusão social e definir penas distintas considerando a posse de drogas para consumo pessoal ou tráfico.

Contudo, apesar dos avanços, é possível identificar disputas de poder, contradições e conflitos no âmbito das conformações políticas sobre drogas. Assim, há oposição ao caráter descriminalizante da Lei $n^{0} 11.343$ a partir da compreensão de que esse documento adota uma lógica patologizante à medida que utiliza os termos "usuário" e "dependente" de forma intercambiável (M. B. Silva \& Delduque, 2015). Observa-se o conflito entre os diferentes atores que participam do processo de construção das políticas sobre drogas, a exemplo da Secretaria Nacional de Políticas sobre Drogas (SENAD), o Ministério da Saúde e entidades de representação profissional, mobilizando setores da sociedade e discursos dicotômicos entre proibição e Redução de Danos (M. A. B. Silva \& Abrahão, 2020). A tensão entre proibicionismo e antiproibicionismo se faz presente em diversas normativas deste século, a exemplo da possibilidade de financiamento público das Comunidades Terapêuticas e sua inserção na Rede de Atenção Psicossocial (Teixeira et al., 2017), o que caminha na direção oposta das conquistas do MRPB, considerando que esses equipamentos são caracterizados pelo paradigma higienista (Bolonheis-Ramos \& Boarini, 2015). 
Considerando a atual conjuntura antirreformista que aponta para a remanicomialização da assistência em saúde (Guimarães \& Rosa, 2019), e a compreensão de que os documentos normativos são construídos a partir de processos histórico-sociais que mobilizam disputas de poder, este artigo tem por objetivo apontar as contribuições da Análise de Discurso Crítica (ADC) para o estudo de um documento normativo sobre drogas. Por se tratar de um estudo derivado de uma pesquisa mais ampla em andamento, o presente relato levará em conta a a análise de apenas um documento: a Lei $n^{\circ}$ 13.840, de 5 de junho de 2019.

\section{METODOLOGIA}

O estudo consiste em uma pesquisa documental (Gil, 2018) de abordagem qualitativa que parte da premissa de que o discurso apresenta uma relação dialética com a estrutura social (Bosi \& Macedo, 2014). Dessa forma, o discurso é influenciado pela estrutura social ao mesmo tempo que a constrói, podendo reproduzi-la ou transformá-la (Fairclough, 2010, 2016). Assim, compreende-se que as políticas sobre drogas e as concepções acerca do uso de drogas são construídas a partir de discursos que englobam mecanismos complexos de relações de poder e embates ideológicos a partir dos quais emerge a hegemonia de certos discursos sobre outros posicionamentos de resistência. O próprio uso de drogas pode ser considerado um fenômeno sócio-histórico com implicações para a política, economia e saúde, bem como as distintas facetas do proibicionismo na história mundial (Carneiro, 2005, 2018; Minayo \& Deslandes, 1998).

\subsection{Análise de Discurso Crítica (ADC)}

Existem diversas correntes e orientações de análise de discurso cujo denominador comum, em oposição à linguística formal, é a compreensão da linguagem como prática social (Neves, 1997). A proposta de Fairclough (2016) situa-se no campo da ciência social crítica e da pesquisa crítica, (Chouliaraki \& Fairclough, 1999) enquadrando-se na ADC a partir da compreensão da propriedade construtiva do discurso e de que este é moldado pelas relações de poder e ideologias (I. Magalhães, 2005). Dessa forma, o discurso é relevante para a construção de identidades sociais e posições de sujeitos (função identitária), de relações sociais entre as pessoas (função relacional) e dos sistemas de crenças e conhecimento (função ideacional). A propriedade construtiva do discurso deve ser considerado ao longo da análise (Fairclough, 2016). 
Fairclough (2016) propoe uma análise pautada em um modelo tridimensional, buscando conciliar a análise textualmente orientada com uma teoria social do discurso. Dessa forma, compreende o discurso - que pode ser expresso tanto pela linguagem escrita, falada ou pictórica - como um modo de ação sobre o mundo e de representação do mesmo, evocando sua relação dialética com a estrutura social (Fairclough, 2010, 2016). A análise tridimensional proposta engloba nove categorias, sendo divididas de acordo com as seguintes dimensões: a) texto: vocabulário, gramática, coesão e estrutura textual; b) prática discursiva: força, coerência e intertextualidade; c) prática social: ideologia e hegemonia (Fairclough, 2016).

Considerando a dimensão do texto, a análise do vocabulário diz respeito às palavras utilizados, ou seja, seu significado, a criação de palaras (lexicalização) e o uso de metáforas. A análise da gramática engloba a forma como as palavras são organizadas em orações, incluindo a relação entre sujeito e objeto (transitividade), e o elemento central da oração (tema). A análise da coesão diz respeito aos conectivos utilizados para organizar as orações em frases a fim de compreender a argumentação utilizada e a identidade social construída ao longo do texto. Por fim, a estrutura textual envolve a organização mais ampla do texto em relação à organização das ideias e sua distribuição ao longo dos parágrafos (Fairclough, 2016).

A dimensão da prática discursiva diz respeito aos mecanismos de produção, distribuição e consumo dos textos, além das categorias força, coerência e intertextualidade. A força diz respeito à ação que é convocada a partir do enunciado analisado. A coerência consiste no sentido atribuído ao texto de acordo com sua produção e consumo. Parte-se da premissa de que o discurso é produzido com a finalidade de alcançar determinado público. Assim, as identidades construídas no discurso são elaboradas a fim de fazer sentido para o público que se deseja alcançar. A intertextualidade, por sua vez, é a propriedade de o discurso ser produzido a partir de fragmentos de outros textos, seja de forma explícita ou não (Fairclough, 2016).

A dimensão da prática social engloba as categorias ideologia, compreendida como modo de construção da realidade que pode contribuir para a produção, reprodução e transformação das relações de dominação, e hegemonia, que diz respeito à negociação de alianças para reafirmar, ou não, as relações de poder e dominação (Fairclough, 2016). Apesar da estrutura complexa do modelo tridimensional de análise proposto, deve-se destacar que a 
ênfase do método proposto por Fairclough é a mudança social que pode ser observada nas mudanças discursivas em vista da emancipação (Fairclough, 2016; C. M. Magalhães, 2001).

\subsection{Seleção do corpus da pesquisa}

O documento base para o presente estudo é a Lei $n^{\circ} 13.840$, de 5 de junho de 2019, que altera diversas normativas da política sobre drogas para dispor sobre as condições de atenção aos usuários ou dependentes de drogas e para tratar do financiamento das políticas. Parte-se da compreensão de que este documento acentua as tensões paradigmáticas presentes nas políticas sobre drogas (Teixeira et al., 2017) à medida que apresenta dispositivos que ameaçam as conquistas do MRPB e endossam o movimento antirreformista da conjuntura atual (Guimarães \& Rosa, 2019; Nunes et al., 2019). Assim, a fim de ampliar a discussão contemporânea sobre a oposição às conquistas do MRPB, considerou-se que a análise deste material a partir da ADC segundo o referencial de Fairclough (2016) possibilitaria a compreensão das marcas ideológicas presente na produção deste discurso e como este representa o fenômeno do uso de drogas e os elementos que o circundam, a exemplo da prevenção e intervenção.

Dessa forma, considerando as peculiaridades da produção de um documento normativo, o corpus da pesquisa foi constituído pelos artigos $8^{\circ}-\mathrm{D}, 23-\mathrm{A}$ e 26-A da Lei $\mathrm{n}^{\circ}$ 13.840, selecionados principalmente por apresentarem rupturas mais sensíveis com as outras leis, portarias e decretos sobre drogas que o precederam, e a Mensagem $n^{\circ} 239$, de 5 de junho de 2019, que contém os dispositivos vetados da lei analisada, as razões do veto e os órgãos governamentais que se manifestaram a favor destes.

\subsection{Análise documental}

A leitura dos documentos foi sucedida pela elaboração de um quadro para sistematizar os órgãos governamentais que se manifestaram pelo veto dos dispositivos e as justificativas mais utilizadas. Os dispositivos da Lei que se destacaram durante a leitura foram transcritos em um documento de texto compartilhado entre os autores juntamente com o texto dos dispositivos vetados. Os enunciados ou palavras foram grifados em duas cores distintas, uma para aqueles cuja contribuição para a política sobre drogas foi considerada positiva e outra para aqueles que apresentavam alguma ameaça e/ou contradição às conquistas do MRPB. Optou-se por utilizar palavras e expressões entre aspas a fim de preservar a forma como se encontram no documento estudado. 
Quadro 1. Enunciado dos dipositivos analisados

\begin{tabular}{|c|c|}
\hline Dispositivo & Enunciado \\
\hline Art. $8^{\circ}-\mathrm{D}$, inciso II & $\begin{array}{l}\text { São objetivos do Plano Nacional de Políticas sobre Drogas, dentre outros: } \\
\text { II - viabilizar a ampla participação popular na formulação, implementação } \\
\text { e avaliação das políticas sobre drogas. }\end{array}$ \\
\hline Art. $8^{\circ}-\mathrm{F}$ (vetado) & $\begin{array}{l}\text { Os membros dos conselhos de políticas sobre drogas serão escolhidos } \\
\text { para mandato de } 2 \text { (dois) anos, na forma de regulamentação específica, } \\
\text { observados o seguintes requisitos: I - idade superior a } 18 \text { anos; e II - } \\
\text { residência na região geográfica abrandiga pelo conselho de políticas sobre } \\
\text { drogas para o qual foi indicado. }\end{array}$ \\
\hline Art. 23-A & $\begin{array}{l}\text { O tratamento do usuário ou dependente de drogas deverá ser ordenado } \\
\text { em uma rede de atenção à saúde, com prioridade para as modalidades de } \\
\text { tratamento ambulatorial, incluindo excepcionalmente formas de internação } \\
\text { em unidades de saúde e hospitais gerais nos termos de normas dispostas } \\
\text { pela União e articuladas com os serviços de assistência social e em } \\
\text { etapas que permitam: }\end{array}$ \\
\hline Art. 23-A, inciso II & $\begin{array}{l}\text { Orientar-se por protocolos técnicos predefinidos, baseados em evidências } \\
\text { científicas, oferecendo atendimento individualizado ao usuário ou } \\
\text { dependentes de drogas com abordagem preventiva e, sempre que } \\
\text { indicado, ambulatorial; }\end{array}$ \\
\hline $\begin{array}{l}\text { Art. 23-A, } \S 3^{\circ} \text {, inciso } \\
\text { II }\end{array}$ & $\begin{array}{l}\text { Internação involuntária: aquela que se dá, sem o consentimento do } \\
\text { dependente, a pedido de familiar ou do responsável legal ou, na absoluta } \\
\text { falta deste, de servidor público da área da saúde, da assistência social ou } \\
\text { dos órgãos públicos integrantes do Sisnad, com exceção de servidores da } \\
\text { área de segurança pública, que constate a existência de motivos que } \\
\text { justifiquem a medida. }\end{array}$ \\
\hline $\begin{array}{l}\text { Art. 23-A, } \S 4^{\circ} \text {, inciso } \\
\text { III }\end{array}$ & $\begin{array}{l}\text { [A internação involuntária] perdurará apenas pelo tempo necessário à } \\
\text { desintoxicação, no prazo máximo de } 90 \text { (noventa) dias, tendo seu término } \\
\text { determinado pelo médico responsável. }\end{array}$ \\
\hline Art. 26-A & $\begin{array}{l}\text { O acolhimento do usuário ou dependente de drogas na comunidade } \\
\text { terapêutica acolhedora caracteriza-se por: I - oferta de projetos } \\
\text { terapêuticos ao usuário ou dependente de drogas que visam à } \\
\text { abstinência; II - adesão e permanência voluntária, formalizadas por } \\
\text { escrito, entendida como uma etapa transitória para a reinserção social e } \\
\text { econômica do usuário ou dependente de drogas; III - ambiente } \\
\text { residencial, propício à formação de vínculos, com a convivência entre os } \\
\text { pares, atividades práticas de valor educativo e a promoção do } \\
\text { desenvolvimento pessoal, vocacionada para acolhimento ao usuário ou } \\
\text { dependente de drogas em vulnerabilidade social; IV - avaliação médica } \\
\text { prévia; V - elaboração de plano individual de atendimento na forma do art. } \\
\text { 23-B desta Lei; e VI - vedação de isolamento físico do usuário ou } \\
\text { dependente de drogas. }\end{array}$ \\
\hline
\end{tabular}

\subsection{Aspectos éticos}

O estudo dispensa aprovação por Comitê de Ética em Pesquisa segundo a Resolução CNS/MS 466/12 porque não envolve seres humanos e os documentos utilizados estão disponíveis em domínio público. 


\section{RESULTADOS E DISCUSSÃO}

Observa-se a presença de medidas de controle sobre a vida de pessoas que apresentam necessidades decorrentes do uso de álcool e outras drogas, e o distanciamento dos dispositivos de participação e controle social, conforme os princípios do Sistema Único de Saúde (Aguiar, 2015), em vista da concentração do poder de decisão na esfera do Poder Executivo. Destaca-se a ameaça dos dispositivos referentes a internação involuntária e ao acolhimento em comunidades terapêuticas às conquistas do MRPB, como a consideração dos direitos humanos e da cidadania da população assistida no âmbito das políticas de saúde mental.

O vocabulário utilizado no documento pode gerar insegurança na execução das políticas políticas sobre drogas, na medida em que abre margem para interpretações distintas e constrói uma identidade humanizada para propostas de tratamento que adotam características de instituições totais (Damas, 2013; Pacheco \& Scisleski, 2013; Ribeiro \& Minayo, 2015); sendo, ainda, opostas às privilegiadas pelo MRPB. Busca-se, assim, atenuar as divergências paradigmáticas. Dessa forma, a descrição da internação involuntária é semelhante a da Lei $n^{\circ} 10.216$ (Brasil, 2001), mas o documento abre margem para que servidores públicos da área da saúde e assistência social possam solicitar este procedimento sem o consentimento da pessoa a ser internada e altera o tempo máximo de internação de 15 dias para até 90 dias, quando comparado com a Portaria n 2.197 (Brasil, 2004).

Nessa perspectiva, as Comunidades Terapêuticas (CT), por sua vez, são adjetivadas como "acolhedoras" ao longo de todo o dispositivo e descritas como "ambiente residencial" de "adesão voluntária" precedida por "avaliação médica", sendo uma "etapa transitória", em vista da "reinserção social" e "abstinência". Evita-se o termo "internação" e proíbe-se o "isolamento físico". Ademais, o vocabulário impreciso também constrói identidades distintas quanto o público-alvo dessas modalidades de tratamento. Assim, a internação involuntária é destinada aos "dependentes" enquanto o público-alvo da CT inclui "usuários ou dependentes de drogas".

A dimensão da prática discursiva reitera as inseguranças geradas pela Lei quanto à assistência. Enquanto documento normativo, observa-se que a força dos dispositivos assume um caráter imperativo: devem nortear a assistência. Contudo, contradizem os dispositivos de documentos precedentes (intertextualidade) que compõem a política sobre 
drogas, principalmente no que diz respeito à distinção entre "usuário", "pessoa em uso indevido", "dependente" e "traficante" (Brasil, 2002), o reconhecimento da Redução de Danos (RD) como forma de ação e resultado desejável (Brasil, 2002, 2004, 2005, 2006, 2007, 2009, 2011), e a ênfase ao tratamento hospitalar ou em CT em detrimento dos serviços da atenção psicossocial especializada e os serviços residenciais de caráter transitório como a Unidade de Acolhimento (Brasil, 2011; BRASIL, 2012).

Dessa forma, a coerência do documento estudado reside na conformidade com o discurso de grupos que se opõem ao MRPB e almejam o recuo de suas conquistas: a expansão dos serviços substitutivos e da RD. O discurso construído na Lei $\mathrm{n}^{\circ} 13.840$ tem por público-alvo os grupos que se beneficiam com a ênfase ao tratamento ambulatorial, hospitalar ou em CT pautados por um paradigma proibicionista.

A prática social produzida pelo documento é a reprodução de elementos ideológicos alinhados com a lógica asilar em detrimento da psicossocial, os quais são manifestados na internação involuntária de dependentes de drogas e na CT como instrumentos de dominação e controle. Deve-se destacar que o documento estudado foi protocolado na Câmara como Projeto de Lei (PL) em 2010 e foi enviado ao Senado em 2013. Portanto, a aprovação do PL deve ser compreendida à luz da atual conjuntura política e a mobilização de alianças em vista de interesses comuns por parte dos atores envolvidos.

Apesar das conquistas do MRPB na mudança do modelo de assistência em saúde mental e na saúde pública de forma geral, observa-se a persistência de disputas paradigmáticas no campo das políticas sobre drogas ao longo do século XXI (Teixeira et al., 2017). A abertura à lógica da RD, sobretudo a partir de uma mudança no cenário político em 2002 (Fiore, 2005), e ao modelo de atenção psicossocial tem sido constantemente sabotada pela oposição contrarreformista. Destaca-se a inserção gradativa das CT nas políticas públicas, a criação de equipes ambulatoriais de média complexidade desvinculadas do cuidado territorial, a ampliação do financiamento para CT e leitos para internação, inclusive em hospitais psiquiátricos, a redução no cadastramento de Centros de Atenção Psicossocial Álcool e outras Drogas (CAPSad) e a condenação da RD (Delgado, 2019; Guimarães \& Rosa, 2019; Nunes et al., 2019; Teixeira et al., 2017). É notável a ênfase em modelos patogolizantes e moralizantes em detrimento do psicossocial.

Os dispositivos da Lei $\mathrm{n}^{\circ} 13.840 / 2019$ reiteram os ataques ao modelo psicossocial, evidenciando uma mudança discursiva de oposição ao MRPB. Nesse contexto, torna-se 
oportuno o uso da ADC para evidenciar os elementos ideológicos de um discurso que se apresenta como anti-ideológico à medida que se esconde sob a premissa de ser pautado por evidências científicas. Contudo, reproduz um conjunto de crenças e de conhecimento que representa a pessoa com necessidades decorrentes do uso de álcool e outras drogas a partir do modelo médico/asilar e moral. As CT, por exemplo, são instituições pautadas por um modelo moral/religioso que demandam maior estudo, profissionalização e fiscalização, considerando relatos de violação dos direitos humanos (Perrone, 2014; CFP, 2018; Ribeiro \& Minayo, 2015; Scaduto, Barbieri, \& Santos, 2015).

O método de análise tridimensional de Fairclough (2006) e sua concepção de análise de discurso permitiu identificar os elementos ideológicos presentes em um documento elaborado e aprovado por grupos que procuram sustentar um discurso ideologicamente neutro. Assim, utiliza-se de recursos para atenuar a ruptura com a política anterior. Observase, por exemplo, que o vocabulário utilizado ao longo do documento tem por construir uma identidade humanizada da CT, afastando-a de suas características de instituição total, e se utiliza da intertextualidade para justificar a internação involuntária de "dependentes de drogas".

Considerando o exposto acima, convém destacar que a interpretação do discurso construído na Lei analisada deve englobar o processo de construção de um documento normativo e a relação, seja de continuidade ou ruptura com outros dispositivos legais. Dessa forma, é necessário estar atento às articulações e relações no âmbito da política que se fazem necessárias em vista da aprovação de um projeto de lei no Congresso. Contudo, diante do contexto de mudança de governo, também torna-se oportuno analisar as alterações na forma de conceber os problemas que as políticas públicas visam responder (Resende, 2018).

Observa-se, então, que a mudança discursiva expressa pela Lei $n^{0} 13.840$ está alinhada com um sistema de crenças e conhecimento - e, portanto, ideológico - que, sob a justificativa de ser pautado por evidências científicas, privilegia uma concepção proibicionista, quanto ao uso de drogas, asilar e moral, a respeito do tratamento, e autoritária, quanto ao modo de produção da política em detrimento de uma trajetória construída a partir da participação popular com ênfase no cuidado territorial e comunitário, considerando a cidadania e os direitos humanos (Nunes et al., 2019). 
Ademais, considera-se que o método empregado fornece subsídios teórico-metodológicos amplos para analisar e compreender fenômenos complexos como a produção discursiva no âmbito da elaboração de documentos normativos.

\section{CONCLUSÕES}

A análise dos fragmentos da Lei $n^{\circ} 13.840$ e da Mensagem $n^{\circ} 239$ permitiu emergir as divergências discursivas entre o entendimento das políticas públicas do Brasil em relação ao que vinha sendo construído como linha de cuidado aos usuários de álcool, crack e outras drogas no país. A inserção das CT e do modelo de intervenção focado na abstinência tem sido validado pelo discurso conservador e autoritário do atual governo brasileiro. Ao adjetivar as CT como "acolhedoras" de "etapa transitória" com vistas à "reinserção social" o eufemismo construído em torno de equipamentos reconhecidos por seu caráter autoritário tem levantado barreiras que a Reforma Psiquiátrica ao longo dos anos buscou reduzir. Salienta-se que a Análise de Discurso proposta por Fairclough foi essencial no processo de compreender a propriedade construtiva do discurso ao elucidar, através de sua metodologia, as relações de poder e validação construídas na letra da lei.

Agradecimentos. Ao Programa de Pós-Graduação em Saúde Coletiva da Universidade de Fortaleza pela iniciativa de organizar um curso de aperfeiçoamento na teoria de Análise de Discurso Crítica com a professora doutora Suely Ferreira Deslandes. Às professoras doutoras Aline Veras Morais Brilhante e Christina César Praça Brasil pelas orientações na construção deste trabalho.

\section{Referências}

Aguiar, Z. N. (2015). O Sistema Único de Saúde e as Leis Orgânicas da Saúde. In Z. N. Aguiar (Ed.), SUS: Sistema Único de Saúde - antecedentes, percurso, perspectivas e desafios. (2nd ed., pp. 41-69). São Paulo: Martinari.

Bolonheis-Ramos, R. C. M., \& Boarini, M. L. (2015). Comunidades terapêuticas: "novas" perspectivas e propostas higienistas. História, Ciências, Saúde - Manguinhos, 22(4), 1231-1248. https://doi.org/https://dx.doi.org/10.1590/S0104-59702015000400005

Bosi, M. L. M., \& Macedo, M. A. (2014). Anotações sobre a análise crítica de discurso em pesquisas qualitativas no campo da saúde. Revista Brasileira de Saude Materno Infantil, 14(4), 423-432. https://doi.org/10.1590/S1519-38292014000400012

Brasil. (2001). Lei $\mathrm{n}^{\circ} 10.216$, de 6 de abril de 2001. Retrieved from www.planalto.gov.br/ccivil_03/leis/leis_2001//10216.htm

Brasil. (2002). Decreto $n^{\circ} 4.345$, de 26 de agosto de 2002. Retrieved from www.planalto.gov.br/ccivil_03/decreto/2002/D4345impressao.htm

Brasil. (2004). Portaria $\mathrm{n}^{\circ} 2.197$, de 14 de outubro de 2004. Retrieved from bvsms.saude.gov.br/bvs/saudelegis/gm/2004/prt2197_14_10_2004.html

Brasil. (2005). Portaria $n^{\circ} 1.028$, de $1^{\circ}$ de julho de 2005 . Retrieved from bvsms.saude.gov.br/bvs/saudelegis/gm/2005/prt1028_01_07_2005.html 
Brasil. (2006). Lei no 11.343, de 23 de agosto de 2006. Retrieved from www.planalto.gov.br/ccivil_03/_ato20042006/2006/lei/l11343.htm

Brasil. (2007). Decreto n 6.117, de 22 de maio de 2007. Retrieved from www.planalto.gov.br/ccivil_03/_ato20072010/2007/decreto/d6117.htm

Brasil. (2009). Portaria $\mathrm{n}^{\circ} 1.190$, de 4 de junho de 2009. Retrieved from bvsms.saude.gov.br/bvs/saudelegis/gm/2009/prt1190_04_06_2009.html

Brasil. (2011). Portaria $n^{\circ} 3.088$, de 23 de dezembro de 2011. Retrieved from bvsms.saude.gov.br/bvs/saudelegis/gm/2011/prt3088_23_12_2011_rep.html

Brasil. (2012). Portaria $\mathrm{n}^{\circ}$ 121, de 25 de janeiro de 2012. Retrieved November 5, 2019, from http://bvsms.saude.gov.br/bvs/saudelegis/gm/2012/prt0121_25_01_2012.html

Carneiro, H. (2005). Transformações do significado da palavra "droga": das especiarias coloniais ao proibicionismo contemporâneo. In R. P. Venâncio \& H. Carneiro (Eds.), Álcool e drogas na história do Brasil. (pp. 11-28). São Paulo: Alameda.

Carneiro, H. (2018). Drogas: a história do proibicionismo. São Paulo: Autonomia Literária.

Carvalho, J. C. de. (2014). A emergência da política mundial de drogas: o Brasil e as primeiras conferências internacionais do ópio. Oficina Do Historiador, 7(1), 153. https://doi.org/10.15448/2178-3748.2014.1.15927

Chouliaraki, L., \& Fairclough, N. (1999). Discourse in late modernity: rethinking critical discourse analysis. Edinburgh: Edinburgh University Press.

Conselho Federal de Psicologia (2018). Relatório da inspeção nacional em Comunidades Terapêuticas - 2017. Retrieved from https://doi.org/10.1017/CBO9781107415324.004.

Costa, J. F. (2006). História da psiquiatria no Brasil: um corte ideológico. (5th ed.). Rio de Janeiro: Garamond.

Damas, F. B. (2013). Comunidades Terapêuticas no Brasil: Expansão, Institucionalização e Relevância Social. Revista de Saúde Pública de Santa Catarina; Vol. 6, No 1 (2013), 6(1), 50-65. Retrieved from http://esp.saude.sc.gov.br/sistemas/revista/index.php/inicio/article/view/173/201

Delgado, P. G. (2019). Reforma psiquiátrica: estratégias para resistir ao desmonte. Trabalho, Educação e Saúde, 17(2). https://doi.org/10.1590/1981-7746-sol00212

Fairclough, N. (2010). A dialética do discurso. Revista Teias, 11(22), 225-234.

Fairclough, N. (2016). Discurso e mudança social (2nd ed.). Brasília: Universidade de Brasília.

Fiore, M. (2005). A medicalização da questão do uso de drogas no Brasil: reflexões acerca de debates institucionais e jurídicos. In R. P. Venâncio \& H. Carneiro (Eds.), Álcool e drogas na história do Brasil. (pp. 257-290). São Paulo: Alameda.

Gil, A. C. (2018). Como elaborar projetos de pesquisa (6th ed.). São Paulo: Atlas.

Guimarães, T. de A. A., \& Rosa, L. C. dos S. (2019). A remanicomialização do cuidado em saúde mental no Brasil no período de 2010-2019: análise de uma conjuntura antirreformista. O Social Em Questão, 22(44), 111-138.

Magalhães, C. M. (Ed.). (2001). Reflexões sobre a análise crítica do discurso. Belo Horizonte: Faculdade de Letras, UFMG.

Magalhães, I. (2005). Introdução: a análise de discurso crítica. DELTA: Documentação de Estudos Em Lingüística Teórica e Aplicada, 21(Especial), 1-9.

Minayo, M. C. de S., \& Deslandes, S. F. (1998). A complexidade das relações entre drogas, álcool e violência. Cadernos de Saúde Pública, 14(1), 35-42. https://doi.org/10.1590/s0102-311x1998000100011

Neves, M. H. de M. (1997). A gramática funcional. São Paulo: Martins Fontes.

Nunes, M. de O., Lima Júnior, J. M. de, Portugal, C. M., \& Torrenté, M. de. (2019). Reforma e contrarreforma psiquiátrica: análise de uma crise sociopolítica e sanitária a nível nacional e regional Psychiatric reform and counter-reform: an analysis of a socio-political and sanitary crisis at national and regional level. Ciência \& Saúde Coletiva, 24(12), 4489-4498. https://doi.org/10.1590/1413-812320182412.25252019 
Pacheco, L. A., \& Scisleski, A. (2013). Vivências em uma comunidade terapêutica. Revista Psicologia e Saúde, 5(2), 165-173.

Perrone, P. A. K. (2014). A comunidade terapêutica para recuperação da dependência do álcool e outras drogas no Brasil: mão ou contramão da reforma psiquiátrica? Ciência \& Saúde Coletiva, 19(2), 569-580. https://doi.org/10.1590/1413-81232014192.00382013

Resende, V. de M. (2018). Análise interdiscursiva de políticas públicas: reflexão epistemológica. Ambitos: Revista Internacional de Comunicación, (39), 57-70.

Ribeiro, F. M. L., \& Minayo, M. C. de S. (2015). As Comunidades Terapêuticas religiosas na recuperação de dependentes de drogas: o caso de Manguinhos, RJ, Brasil. Interface - Comunicação, Saúde, Educação, 19(54), 515-526. https://doi.org/10.1590/1807-57622014.0571

Santos, G. A. dos, \& Queiroz, I. S. (2016). Internação psiquiátrica compulsória de usuários abusivos de drogas: uma falência ao SUS e um desuso da Política de Redução de Danos. Gerais: Revista de Saúde Pública Do SUS/MG, 4(1), 59-69.

Scaduto, A. A., Barbieri, V., \& Santos, M. A. dos. (2015). Adesão aos princípios da comunidade terapêutica e processo de mudança ao longo do tratamento. Psicologia: Ciência e Profissão, 35(3), 781-796. https://doi.org/10.1590/1982-3703000792013

Silva, M. A. B., \& Abrahão, A. L. (2020). Política de Atenção Integral aos usuários de álcool e outras drogas: uma análise guiada por narrativas. Interface - Comunicação, Saúde, Educação, 24, 1-14.

Silva, M. B., \& Delduque, M. C. (2015). Patologização e penalização do uso de drogas: uma análise socioantropológica de proposições legislativas (2007-2010). Physis Revista de Saúde Coletiva, 25(1), 231250. https://doi.org/http://dx.doi.org/10.1590/S0103-73312015000100013

Teixeira, M. B., Ramôa, M. de L., Engstrom, E., \& Ribeiro, J. M. (2017). Tensões paradigmáticas nas políticas públicas sobre drogas: análise da legislação brasileira no período de 2000 a 2016. Ciência \& Saúde Coletiva, 22(5), 1455-1466. https://doi.org/10.1590/1413-81232017225.32772016

Vargas, A. de F. M., \& Campos, M. M. (2019). A trajetória das políticas de saúde mental e de álcool e outras drogas no século XX. Ciência \& Saúde Coletiva, 24(3), 1041-1050. https://doi.org/10.1590/141381232018243.34492016 